\title{
Information and News
}

\section{MEETINGS}

- XXII International Symposium of Morphological Sciences: Sao Paulo, Brazil, February 12 to $16,2012$.

- $12^{\text {th }}$ Congress of the European Association of Clinical Anatomy: Lisboa, Portugal, July 2013.

- 18th Congress of the International Federation of Associations of Anatomists (IFAA): Beijing, China, August 8 to 10, 2014. www.bicc.com.cn y www.bcghotel.com.

\section{CALL TO SUBMISSION}

\section{JOURNAL COVER PAGE}

We invite all subscribers to the "Revista Argentina de Anatomía Clínica" (Argentine Journal of Clinical Anatomy) and the members of the "Asociación Argentina de Anatomía Clínica" (Argentine Association of Clinical Anatomy) to send images (photographs, drawings, cartoons, etc.) to be included in the cover page of the journal.

Images must be original, related to Clinical Anatomy, Medical Education in Anatomy, contents or activities of the "Revista Argentina de Anatomía Clinica" or activities of the "Asociación Argentina de Anatomía Clìnica" (AAAC), have good enough quality for the purpose of editing, suit the available space, have not been published formally or informally (e.g. internet) in advance, have a title and author's name.

The images will be sent through the website of the Journal. They will be selected by the Editor in Chief and the Editorial Board. Where considered appropriate, participation may be asked to the subscribers. Your images will lead next issues

Prof. Dr. Susana N. Biasutto

Editor in Chief

Revista Argentina de Anatomía Clínica 


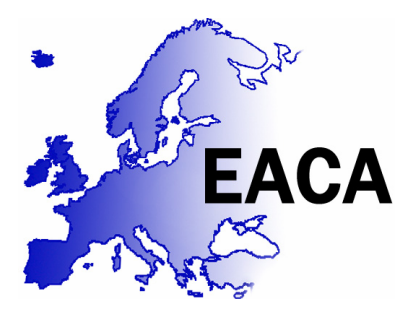

\title{
EUROPEAN ASSOCIATION OF CLINICAL ANATOMY
}

\author{
Univ.Prof. Dr.med. Andreas H. WEIGLEIN \\ EACA-Councilor \& International Congress Coordinator \\ Institute of Anatomy, Vice Chair \\ Medical University Graz \\ Harrachgasse 21, A-8010 Graz, Austria, Europe \\ Tel.: ++433163804210 Fax: ++433163809620 \\ e-mail: andreas.weiglein@medunigraz.at
}

2011-08-02

Dear Mrs. Ex-President Prof. Biasutto,

Dear Council Members of the AAAC,

Dear Members of the AACA,

The $12^{\text {th }}$ Congress of the European Association of Clinical Anatomy (EACA) will take place in Lisboa, Portugal in the first half of July, 2013. The congress will be organized by Prof. Dr. Antonio Jose Goncalves-Ferreira and his team.

It is with great pleasure that I, on behalf of the EACA-Council and on behalf of the Congress Organising Team invite you - the members of the Asociación Argentina de Anatomía Clínica - to participate and contribute to this international congress that covers a wide variety of topics like clinical anatomy, functional histology, sports anatomy, kinesiolgy, anatomical techniques, and anatomical basis for anaesthesiology, surgery and radiology and medical education.

After more than five years of the AAAC it should be a good idea to join other international groups to see that we are facing similar challenges worldwide, but strategies may be different. And finally, the larger the group the stronger we are.

I wish you a very nice, interesting and fruitful congress in Tucuman. I am deeply sorry that I cannot be with you, but I have to run a surgical training course on the spine with 180 international participants at the same time of your conference.

Yours sincerely,

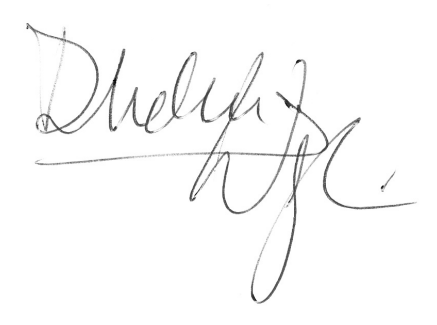

Andreas H. WEIGLEIN

EACA Councilor \& International Congress Coordinator 


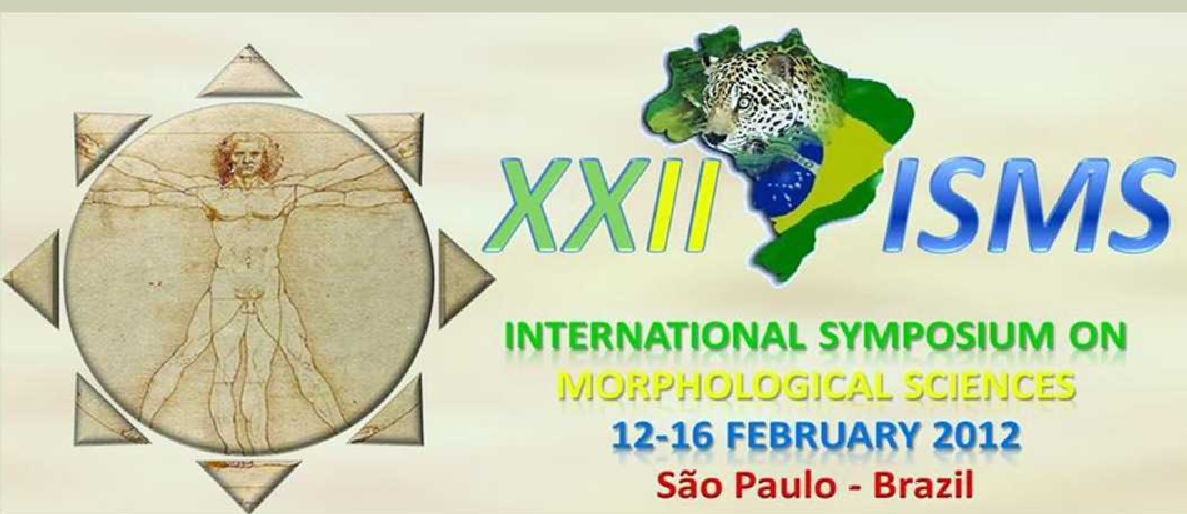

th 7September, 2011. Dear Professor,

On behalf of the Symposium Organizing Committees, it gives us great pleasure to invite you and a 17 the teachers and students of your Department to participate in the coming XXII International Symposium on Morphological sciences to be held in São Paulo, Brazil from February 12 to 16, 2012.

The central theme of this edition is "Morphology - From the Lab to the Bedside" with the aim of exploring the important applications of this biological field for nowadays health care and science development. Moreover, in this twenty-second edition, there will be special participations of the Federative International Program for Anatomical Terminology (FIPAT) of the International Federation of Associations of Anatomists (IFAA), Ibero-Latinamerican Symposium of Anatomical Terminology (SILAT) of the Panamerican Association of Anatomy (APA) and world Association of Veterinary Anatomists (WAVA).

thIn closing, we would be pleased and honored if you would attend the meeting and help us in advertising this symposium among your friends and colleagues. The deadline for abstract submission is october 7, 2011. Receive our best wishes,

Prof. Dr. Maurício Moscovici

Honorary President of the XXII International Symposium on Morphological Sciences

Prof. Dr. Richard Halti Cabral

President of the XXII International Symposium on Morphological Sciences

Website: http://ismsxxii.webs.comE-mail:

\section{ismsxxii@gmail.com}
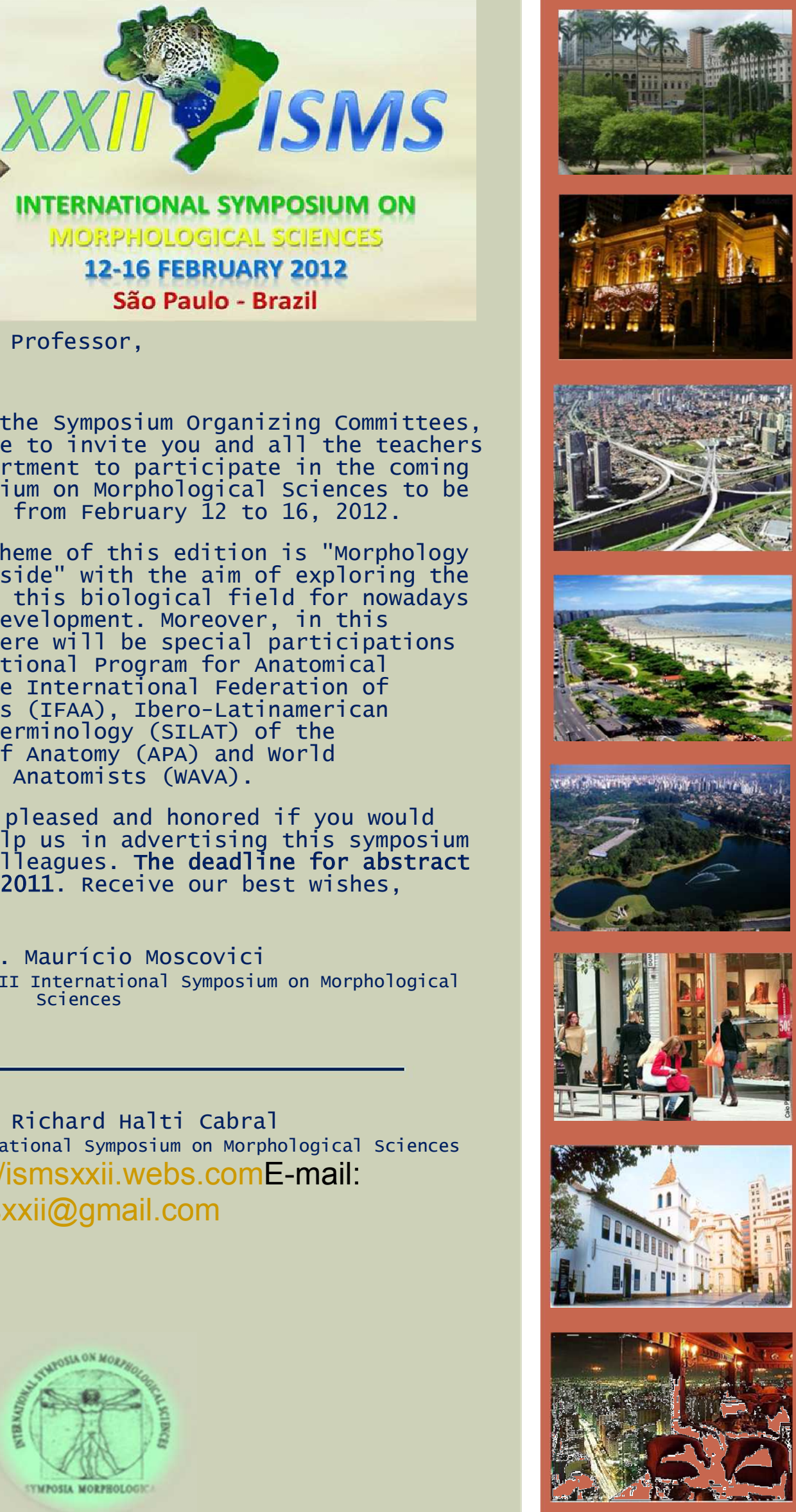